\title{
Polatuzumab Vedotin
}

\author{
National Cancer Institute
}

\section{Source}

National Cancer Institute. Polatuzumab Vedotin. NCI Thesaurus. Code C104153.

An antibody-drug conjug ate (ADC) composed of a monoclonal antibody directed against B-cell antigen receptor complex-associated protein beta chain (CD79B) conjug ated, via a protease-cleavable peptide linker, to monomethyl auristatin E (MMAE), an auristatin derivative and a potent microtubule inhibitor, with potential antineoplastic activity. Upon administration, the monoclonal antibody moiety of polatuzumab vedotin selectively binds to CD79B, a protein which is abundantly expressed on the surface of B-cells. Upon internalization and proteolytic cleavage, MMAE binds to tubulin and inhibits its polymerization, resulting in G2/M phase arrest and tumor cell apoptosis. CD79B, a component of the B-cell receptor (BCR), plays a key role in B-cell receptor signaling and is expressed on the surface of almost all types of malignant B-cells. 